\title{
Effects of Carboxylated Multiwalled Carbon Nanotubes on the Function of Macrophages
}

\author{
Xia Dong, Lanxia Liu, Dunwan Zhu, Hailing Zhang, Yingxin Li, and Xigang Leng \\ Tianjin Key Laboratory of Biomedical Materials, Institute of Biomedical Engineering, Chinese Academy of Medical Sciences and \\ Peking Union Medical College, Tianjin 300192, China
}

Correspondence should be addressed to Xigang Leng; lengxgyky@163.com

Received 14 October 2014; Accepted 25 December 2014

Academic Editor: Shuming Zhang

Copyright (C) 2015 Xia Dong et al. This is an open access article distributed under the Creative Commons Attribution License, which permits unrestricted use, distribution, and reproduction in any medium, provided the original work is properly cited.

Multiwalled carbon nanotubes (MWCNTs) have tremendous potential in many areas of research and applications. Modification of MWCNTs with carboxyl group is one of the widely used strategies to increase their water dispersibility. However, the effect of carboxylation of MWCNTs on their interaction with macrophages remains unclear. The current study compared the impact of pristine MWCNTs (p-MWCNTs) and carboxylic acid functionalized MWCNTs (MWCNTs-COOH) on RAW264.7 cells by looking at the cell viability, phagocytic activity, production of cytokines (IL-1 $\beta$, IL-10, IL-12, and TNF- $\alpha$ ), and intracellular reactive oxygen species (ROS). It was revealed that exposure to either p-MWCNTs or MWCNTs-COOH induced decreased viability of murine macrophage RAW 264.7 cells and moderately elevated phagocytic activity of murine peritoneal macrophages, but no statistical significance was found between the two groups. Increased production of ROS in macrophages was induced after exposure to either p-MWCNTs or MWCNTs-COOH. However, no significantly elevated production of cytokines (IL-1 $\beta$, IL-10, IL-12, and TNF- $\alpha$ ) was observed from RAW 264.7 cells after exposure to the CNTs. Those data suggested that modification with carboxyl group did not exert obvious impact on the interaction of MWCNTs with macrophages.

\section{Introduction}

Carbon nanotubes (CNTs), which are usually classified into single-walled carbon nanotubes (SWCNTs) and multiwalled carbon nanotubes (MWCNTs) [1], have won enormous popularity in nanotechnology for their unique properties and applications. The rapid development of nanotechnology has renewed potential applications within commercial, environmental, and medical sectors, including electronic devices, polymer composites, enzymatic films, scaffolds for tissue engineering, and nanoscale constructs for intracellular drug/gene delivery or tracking and detecting diseases [26]. The broad range of increasing applications for CNTs will almost certainly result in increased potential for both human and environmental exposures to these nanomaterials. Therefore, it is essential to ascertain the potential hazards of CNTs to humans and other biological systems. A number of in vivo and in vitro studies have been conducted to evaluate the biological impacts of CNTs. In vivo studies demonstrated that intratracheally introduced CNTs induced granulomas in rat and mice lungs $[7,8]$. Studies on the cytotoxicity of CNTs against a variety of cell lines revealed that CNTs induced elevated release of IL- 8 in human epidermal keratinocytes [9], DNA damage in mouse embryonic stem cells [10], apoptosis of $\mathrm{T}$ lymphocyte [11], and reduced proliferation of rat aortic smooth muscle cells [12].

Generally, metal dissolution, size effect, and surface chemistry have been cited as major factors indicating cytotoxicity of CNTs. Several investigations were conducted on SWCNTs with varying metal content to evaluate their cytotoxicity $[13,14]$. The size, shape, and length of CNTs were also found to significantly impact on the cytotoxicity [15]. Modification of CNTs with different chemical groups was used to enhance their solubility and biocompatibility; each was likely to result in different cytotoxicity [16, 17]. Covalent functionalization by oxidization with strong oxidants to generate carboxylic acid groups or carboxylated fractions on the surface of the CNT is one of the widely used strategies 
to increase their water miscibility. Various molecules can be further coupled to the surface of carboxylated CNTs (CNTs$\mathrm{COOH}$ ) for the desired applications. However, the impact of carboxylation of CNTs on their cytotoxicity is far from being completely understood.

Macrophages are the key cells in mediating the inflammatory responses to foreign substances, especially particulate substances such as nanoparticles, through phagocytosis and secretion of proinflammatory cytokines [18, 19]. Therefore, the interaction of CNTs with macrophages may affect the cytotoxicity of CNTs and could thus be employed to evaluate their biocompatibility. Previous study conducted by Shvedova et al. demonstrated that SWCNTs induced recruitment and activation of macrophages in the lung of exposed animals [20]. Results from other study showed that SWCNTs or MWCNTs were cytotoxic and genotoxic on murine macrophages [21-24] and could cause incomplete phagocytosis or mechanically pierce through the plasma membrane and result in oxidative stress and cell death in human macrophage cells [22].

The current study was aimed at evaluating the impact of carboxylation on the cytotoxicity of CNTs by comparing the interactions of pristine MWCNTs (p-MWCNTs) and carboxylated MWCNTs (MWCNTs-COOH) with murine macrophage cell line RAW264.7 cells. It was revealed that exposure to either p-MWCNTs or MWCNTs-COOH induced decreased viability of murine macrophage RAW 264.7 cells and elevated phagocytic activity of murine peritoneal macrophages, but no statistical significance was found between the two groups. Increased production of ROS in macrophages was induced after exposure to either $\mathrm{p}$ MWCNTs or MWCNTs-COOH. However, no significantly elevated production of cytokines (IL-1 $\beta$, IL-10, IL-12, and TNF- $\alpha$ ) was observed from RAW 264.7 cells after exposure to the CNTs.

\section{Materials and Methods}

2.1. Materials. p-MWCNTs and MWCNTs-COOH were purchased from Chengdu Organic Chemicals Co. Ltd. (Sichuan, China), The MWCNTs were characterized with transmission electron microscope (TEM) (JEM-1010, JEOL, Japan), scanning electron microscope (SEM) (X-650, HITACHI, Japan), and X-ray photoelectron spectroscope (XPS) (PHI1600 ESCA, Perkin-Elmer, USA) in our previous study [25]. It was demonstrated that the two MWCNTs had a similar surface topography and size (average outside diameters of 10 to $20 \mathrm{~nm}$ and average length of 10 to $30 \mu \mathrm{m}$ ). It also revealed the presence of carboxyl groups on the MWCNTs$\mathrm{COOH}$ and the absence of any metal elements on the two kinds of MWCNTs. Murine macrophage cell line RAW264.7 was obtained from ATCC (Manassas, VA, USA). FBS was obtained from Hyclone (Logan, UT, USA). Lipopolysaccharide (LPS) and $2^{\prime}, 7^{\prime}$-dichlorofluorescein (DCF) were purchased from Sigma-Aldrich (St. Louis, MO, USA). CellTiterGlo Luminescent Cell Viability Assay Kits were purchased from Promega (Madison, WI, USA). Immunoassay Kits for murine cytokines (IL-1 $\beta$, IL-10, IL-12, and TNF- $\alpha$ ) were purchased from BioSource International, Inc. (Camarillo, California, USA).

2.2. Preparation of CNT Suspensions. The MWCNTs were dispersed in PBS to prepare stock suspensions $(2 \mathrm{mg} / \mathrm{mL})$ and sonicated (Ultra sonic processor KQ22000DE) at $25^{\circ} \mathrm{C}$, $80 \mathrm{~W}$ for $20 \mathrm{~min}$. The stock suspensions were then heatsterilized. To prepare test concentrations, the solution was sonicated again and then serially diluted with serum-free DMEM medium.

2.3. Cell Viability Assay. RAW264.7 cells were grown in DMEM supplemented with $1 \%$ L-glutamine, $1 \%$ penicillin/streptomycin, and 10\% heat inactivated FBS. The cells wereseeded into a 96-well plate at a density of $5 \times 10^{4}$ cells $/ \mathrm{mL}(100 \mu \mathrm{L}$ per well) and incubated for 24 hours at $37^{\circ} \mathrm{C}$ in a humidified $5 \% \mathrm{CO}_{2}$ incubator. The cells were then divided into 3 groups (6 wells/group) and treated with different concentrations $(1,10,100$, and $200 \mu \mathrm{g} / \mathrm{mL}$, resp.) of p-MWCNTs, MWCNTs-COOH, and fresh medium alone (negative control), respectively, leaving 8 wells without cells as blank control. After 12, 24, 48, and 72 hours of coincubation, $100 \mu \mathrm{L}$ of CellTiter-Glo Reagent was added to each well and incubated at room temperature for 10 minutes to stabilize the luminescent signal. The luminescent intensity was measured in a microtiter plate reader (VARIOSKAN FLASH, Thermo, MA, USA). The viability of cell was calculated with the following formula: cell viability ratio $(\%)=\left(A_{\text {test }}-A_{\text {blank }}\right) /$ $\left(A_{\text {negtive }}-A_{\text {blank }}\right) \times 100$.

2.4. ELISA for Cytokines. RAW264.7 cells were seeded in a 24 -well plate at a density of $5 \times 10^{4}$ cells $/ \mathrm{mL}(2 \mathrm{~mL}$ per well $)$ and coincubated with p-MWCNTs or MWCNTs-COOH at the concentrations of $1,10,100$, and $200 \mu \mathrm{g} / \mathrm{mL}$, respectively. The cells treated with $1 \mu \mathrm{g} / \mathrm{mL}$ LPS were used as the positive control, whereas the untreated cells were employed as the negative control. After 12, 24, 48, and 72 hours of coincubation, aliquots of the cell supernatant were collected, centrifuged, and stored at $-80^{\circ} \mathrm{C}$ for cytokine determination. The concentration of cytokines (IL-1 $\beta$, IL-10, IL-12, and TNF- $\alpha$ ) in the cell supernatant was determined by enzymelinked immunosorbent assay according to the manufacturer's instructions. Optical density was measured at $450 \mathrm{~nm}$ using a microtiter plate reader (VARIOSKAN FLASH, Thermo, MA, USA). Each ELISA test was performed in duplicate and the experiment was repeated three times. The amount of the cytokines in the cell supernatants was calculated by reference to the standard curve constructed with fixed concentrations of the human recombinant cytokines provided in the kits.

2.5. Detection of Phagocytic Activity of the Macrophages. A total of 24 mice ( $25 \mathrm{~g}$, male) were randomly divided into 4 groups (six/group). Groups 1, 2, and 3 were peritoneally injected with $1 \mathrm{~mL}$ of p-MWCNTs $(200 \mu \mathrm{g} / \mathrm{mL})$, MWCNTs$\mathrm{COOH}(200 \mu \mathrm{g} / \mathrm{mL})$, and LPS $(1 \mu \mathrm{g} / \mathrm{mL})$ solution, respectively, leaving group 4 untreated. 24 hours after inoculation, the murine peritoneal macrophages were harvested by centrifugation and suspended in $0.9 \% \mathrm{NaCl}$ solution. 
After that, $50 \mu \mathrm{L}$ of the cell suspension containing $2 \times$ $10^{6}$ cells $/ \mathrm{mL}$ was incubated with equal volume of freshly prepared suspension of 5\% chicken red blood cells (CRBCs) at $37^{\circ} \mathrm{C}$ for 30 minutes. The phagocytosis of the CRBCs by macrophages was observed under a microscope (Leica, Germany) with a magnification of 1000 after staining with Wright-Giemsa. The phagocytic rate (PR) and phagocytic index (PI) were calculated with the following formulas: $\mathrm{PR}=$ (the number of macrophages containing CRBC/total number of the macrophages) $\times 100 \%$; PI $=$ (total number of the phagocytosed CRBC/total number of macrophages).

2.6. ROS Detection. The formation of intracellular ROS was measured by monitoring the increase in the intensity of fluorescence generated by $2^{\prime}, 7^{\prime}$-dichlorofluorescein (DCF). RAW264.7 cells were seeded in a 24-well plate at a density of $5 \times 10^{4}$ cells $/ \mathrm{mL}$ ( $2 \mathrm{~mL}$ per well) and coincubated with $\mathrm{p}$ MWCNTs or MWCNTs-COOH at the concentrations of 1,10 , 100 , and $200 \mu \mathrm{g} / \mathrm{mL}$, respectively, with the cells treated with $100 \mu \mathrm{M} \mathrm{H}_{2} \mathrm{O}_{2}$ as positive control and the untreated cells as negative control. After 12, 24, 48, and 72 hours of coincubation, the cells were washed with PBS twice and subsequently incubated with $500 \mu \mathrm{L}$ DCFH-DA diluted with serum-free medium $(1: 1000)$ for 30 minutes at $37^{\circ} \mathrm{C}$ in a humidified $5 \% \mathrm{CO}_{2}$ incubator. After that, the liquid was removed and the plate was washed with PBS three times to remove the unaffiliated fluorescent probes. $500 \mu \mathrm{L}$ of serum-free medium was added and incubated for 30 minutes at $37^{\circ} \mathrm{C}$, followed by measuring the fluorescent intensity in a microtiter plate reader (VARIOSKAN FLASH, Thermo, USA) with exciting wavelength of $485 \mathrm{~nm}$ and emitting wavelength of $535 \mathrm{~nm}$.

2.7. Statistical Analysis. Data were presented as the mean of six individual observations with standard deviation. The statistical analysis was performed using the ANOVA (a oneway analysis of variance), followed by Bonferroni $t$-test for comparison with the control group. Statistical significance was determined at $P<0.05$.

\section{Results and Discussion}

Knowledge about the biological impact of functionalized CNTs and the underlying mechanisms is crucial for designing CNTs with improved biocompatibility. Increasing efforts have been focused on studying the interaction between functionalized CNTs and cells, but the results remained conflicting. There were several reports showing that oxidation of CNTs was associated with decreased cytotoxicity and improved biocompatibility, while other studies reported that functionalized CNTs were more cytotoxic. Bellucci et al. compared the toxicity of pristine and oxidized MWCNTs on human $\mathrm{T}$ cells and observed that oxidized CNTs were more toxic than pristine CNTs [26]. Jos et al. showed that toxic effects in Caco cells were induced from $100 \mu \mathrm{g} / \mathrm{mL}$ SWCNTs-COOH, but the cytotoxic effect of pristine CNTs at the same concentration was not observed in their study [27]. Liu et al. recently demonstrated that CNTs-COOH induced autophagic cell death in A549 cells through the
AKT-TSC2-mTOR pathway and caused acute lung injury in vivo, whereas polyaminobenzene sulfonic acid-CNT (PABSCNT) and polyethylene Glycol-CNT (PEG-CNT) did not [28]. The effects of carboxylic acid functionalized CNTs on macrophages are of great interest due to the pivotal role macrophages play in the interaction between the body and foreign particulate substances including CNTs. Albeit there have been several studies reporting the interaction between pristine CNTs and macrophages, little information has been accumulated regarding the impact of carboxylic acid functionalized CNT on macrophages. The primary goal of the present study was to investigate the interaction between MWCNTs- $\mathrm{COOH}$ and macrophages.

The divergent findings about the biological effects of functionalized CNTs may attribute to a variety of factors including the sizes and shapes of CNTs, metal impurities, and adsorption of the FBS onto the surface of the CNTs, which can seriously influence the toxicological evaluation of CNT. Therefore, it is pivotally important to characterize the CNTs before toxicity assessment. Both p-MWCNT and MWCNT$\mathrm{COOH}$ employed in the current study were characterized with TEM, SEM, and XPS in our previous investigation [25], which demonstrated the existence of carboxyl group on the surface of MWCNT-COOH, the similarity of MWCNT$\mathrm{COOH}$ with p-MWCNT in morphology and size, and absence of any detectable metal residues on both CNTs. Since CNT might adsorb the FBS proteins in the culture medium and thus lead to decreased cell viability [29], the stock suspension of both CNTs used in the present study was prepared with PBS in an attempt to avoid the adsorption of the FBS proteins in the culture medium onto the surface of the CNTs before coincubation with cells.

While MTT assay has been widely used in the assessment of cell viability, it may result in unreliable results when employed for toxicological evaluation of CNT due to the fact that CNT can interact with formed MTT-formazan crystals and thus interfere with the evaluation of the toxicity of CNTs, leading to quite different results as compared with that utilizing water soluble tetrazolium salts (WST-1) [30]. It was also reported that $\mathrm{CNT}$ can interact with a number of other dyes, including WST-1, Neutral Red, and Alamar BlueTM [31], most likely through physical sorption. This can lead to false reading of the toxicity and make these assays inappropriate for quantitative evaluation of the toxicity of CNT. Therefore, we chose to evaluate the cytotoxicity of the CNTs by CellTiter-Glo Luminescent Cell Viability Assay, which determines the number of active cells based on the luciferase reaction generating a stable "glow-type" luminescent signal, which is not influenced by CNT. As shown in Figure 1, both p-MWCNT and MWCNT-COOH induced decreased viability of RAW264 cells in a dosedependent manner; however, there is no significant difference between the two groups. The CNT at $1 \mu \mathrm{g} / \mathrm{mL}$ was not found to cause any obvious cytotoxicity within 72 hours of exposure. 24 hours of exposure to $10 \mu \mathrm{g} / \mathrm{mL}$ CNTs led to significantly decreased cell viability $(61.46 \pm 3.65 \%$ for MWCNT-COOH and $60.37 \pm 4.41 \%$ for $\mathrm{p}-\mathrm{MWCNT}$ ), and even sharper decrease in cell viability was observed after exposure to 100 and $200 \mu \mathrm{g} / \mathrm{mL}$ of $\mathrm{p}-\mathrm{MWCNT}$ or MWCNT-COOH. However, the 


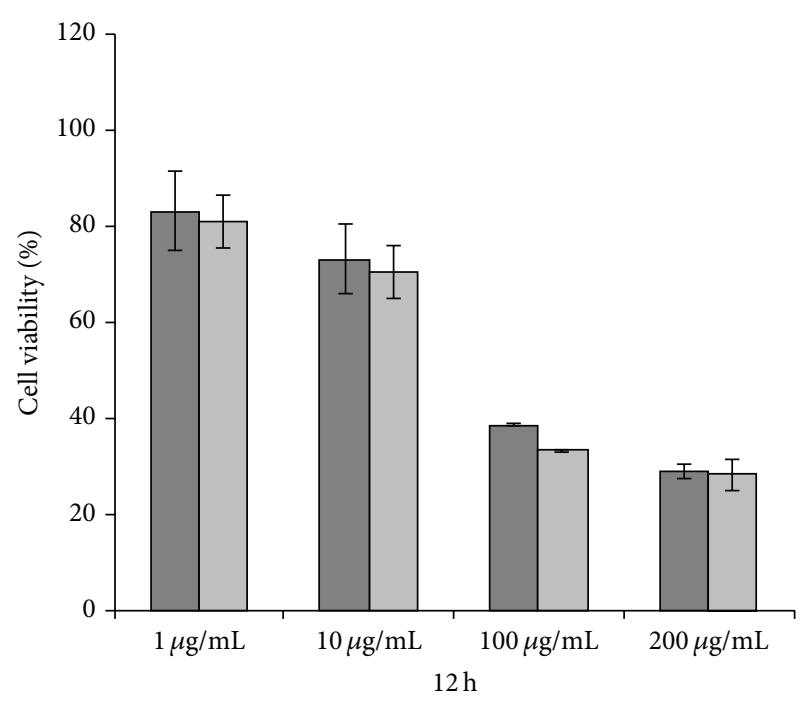

(a)

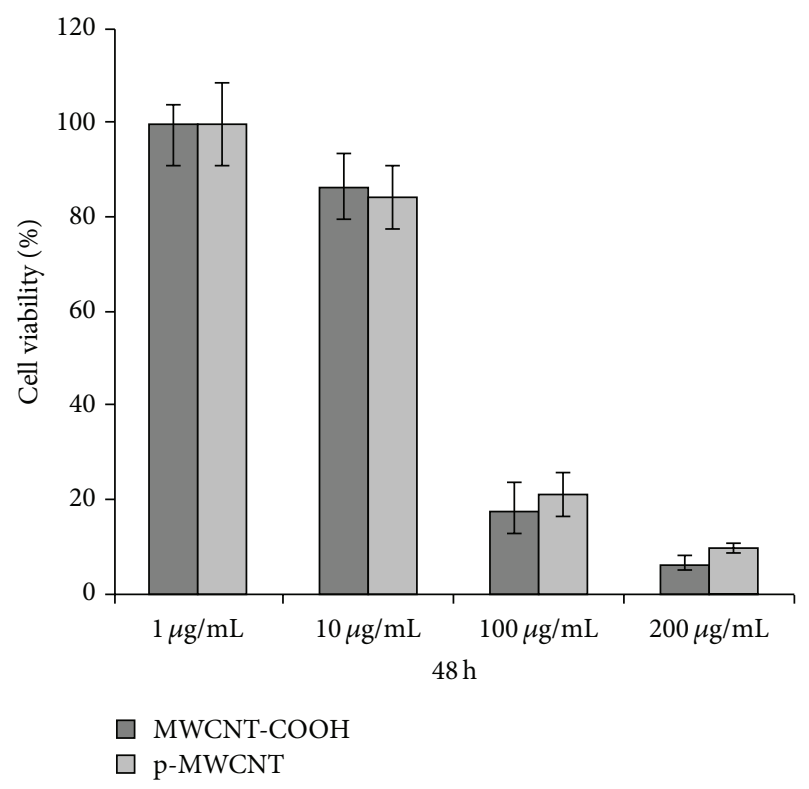

(c)

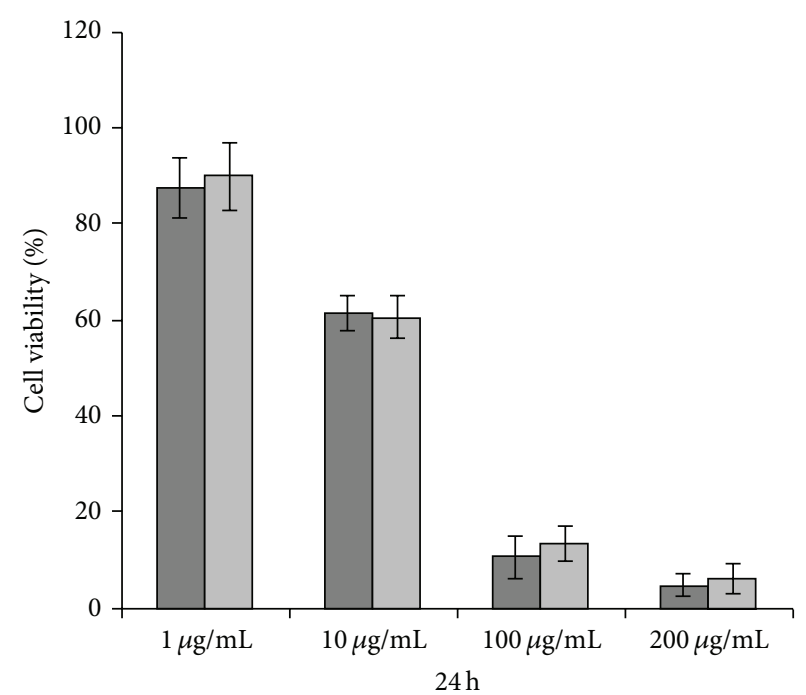

(b)

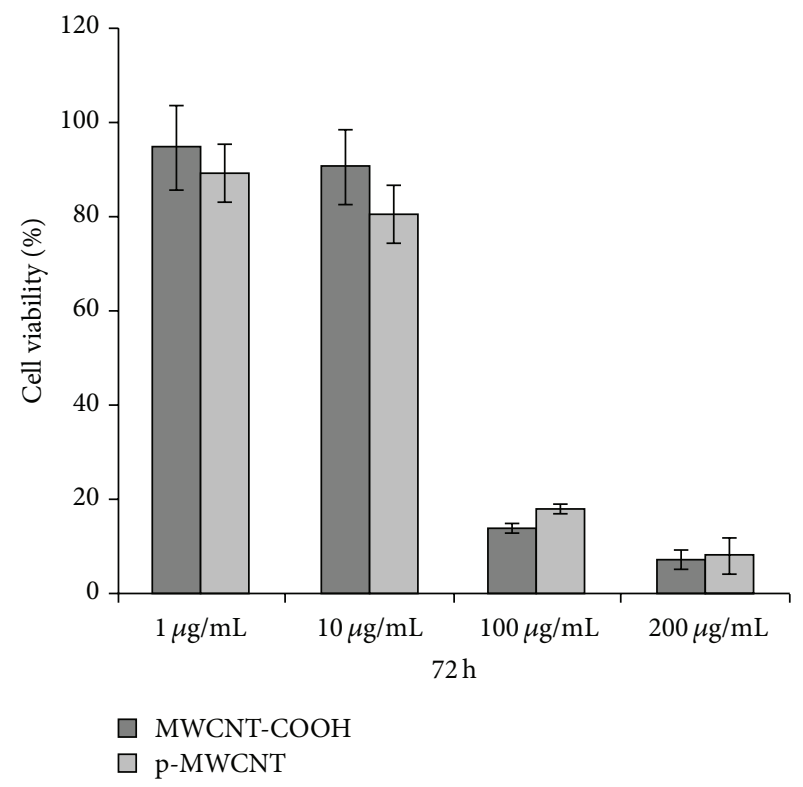

(d)

Figure 1: The effect of p-MWCNTs and MWCNTs-COOH on the cell viability.

cell viability bounced back after 48 hours of exposure $(86.35 \pm$ $7.01 \%$ in MWCNT-COOH group and $84.01 \pm 6.82 \%$ in pMWCNT group). This observation was different from our previous report that MWCNT-COOH was less toxic against normal liver cell line LO2 cells, providing further evidence of the cell type dependence of CNT cytotoxicity [25]. It is also worth noting that the cytotoxicity reached to the highest level after 24 hours of incubation, and after that, cell viability gradually recovered, which indicated that RAW264.7 cells had a self-adaptation and self-renewal process after 24 hours of exposure to p-MWCNT or MWCNT-COOH.

Since macrophages are important cells for mediating the inflammatory responses to foreign particulate substances through phagocytosis and secretion of proinflammatory cytokines, it is also vitally important to learn the impact of MWCNTs-COOH on the cytokine production by macrophages and their phagocytic activity. Four different cytokines were selected in the current study, which included IL-1 $\beta$, IL-10, IL-12, and TNF- $\alpha$. Three of them, including IL$1 \beta$, IL-12, and TNF- $\alpha$, are proinflammatory cytokines which upregulate the inflammatory response [32], whereas IL-10 is an anti-inflammatory cytokine which downregulates the release of cytokines [33, 34]. It was shown from Figure 2 that neither p-MWCNTs nor MWCNTs-COOH induced any significant changes in the production of the 4 cytokines by RAW264.7 cells at the concentrations ranging from 1 to $200 \mu \mathrm{g} / \mathrm{mL}$ for up to 72 hours of coincubation. However, LPS, a strong inflammation-stimulating agent that is able to induce release of inflammatory cytokines by macrophages, induced significantly elevated release of the four cytokines, 


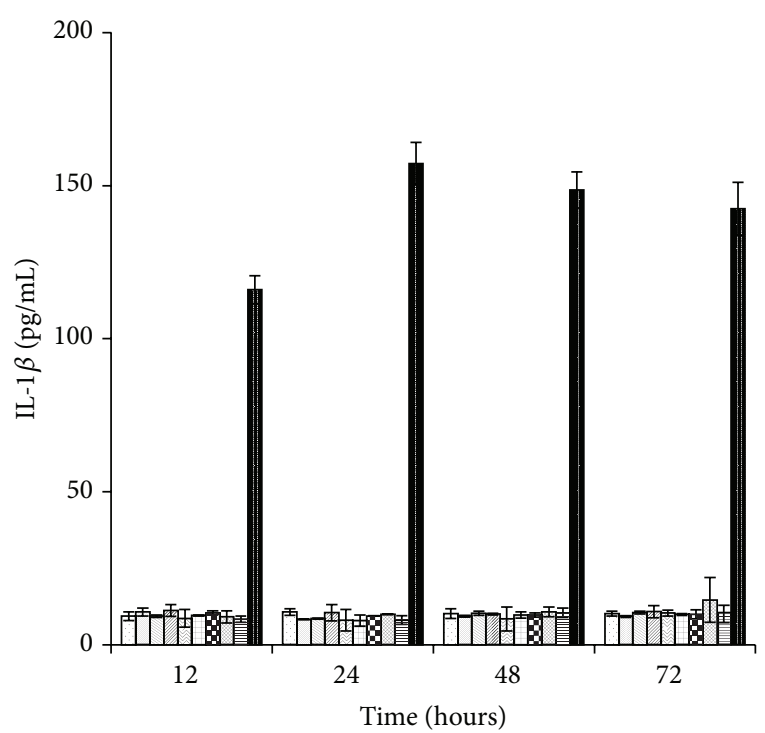

(a)

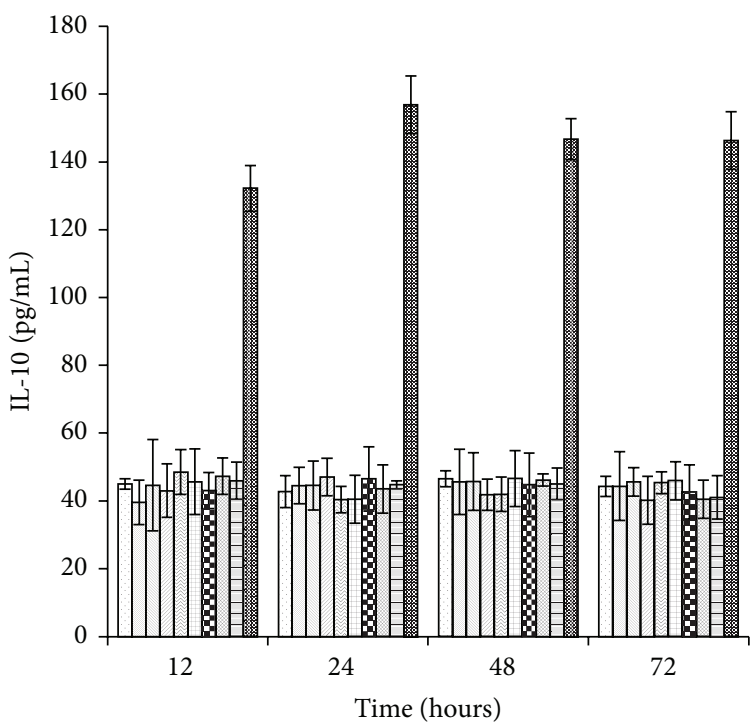
$\square$ Negative control
$\square 1 \mu \mathrm{g} / \mathrm{mL}$ p-MWCNT
$\square 10 \mu \mathrm{g} / \mathrm{mL}$ p-MWCNT
$\square 100 \mu \mathrm{g} / \mathrm{mL}$ p-MWCNT
圆 $200 \mu \mathrm{g} / \mathrm{mL}$-MWCNT

\begin{abstract}
$\square 1 \mu \mathrm{g} / \mathrm{mL}$ MWCNT-COOH
ㅁ $10 \mu \mathrm{g} / \mathrm{mL}$ MWCNT-COOH

- $100 \mu \mathrm{g} / \mathrm{mL}$ MWCNT-COOH

目 $200 \mu \mathrm{g} / \mathrm{mL}$ MWCNT-COOH

ㅁ Positive control
\end{abstract}

(c)

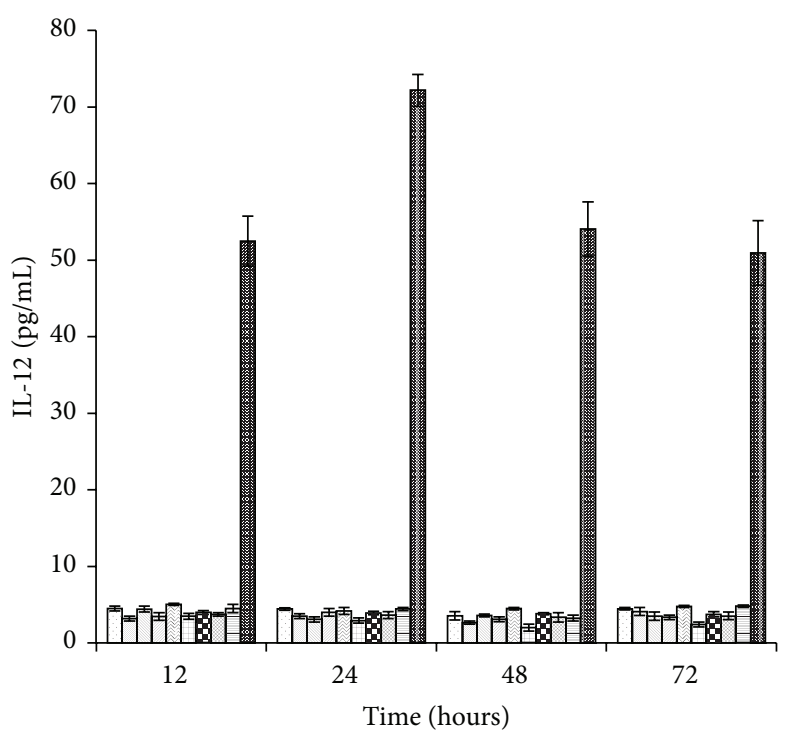

(b)

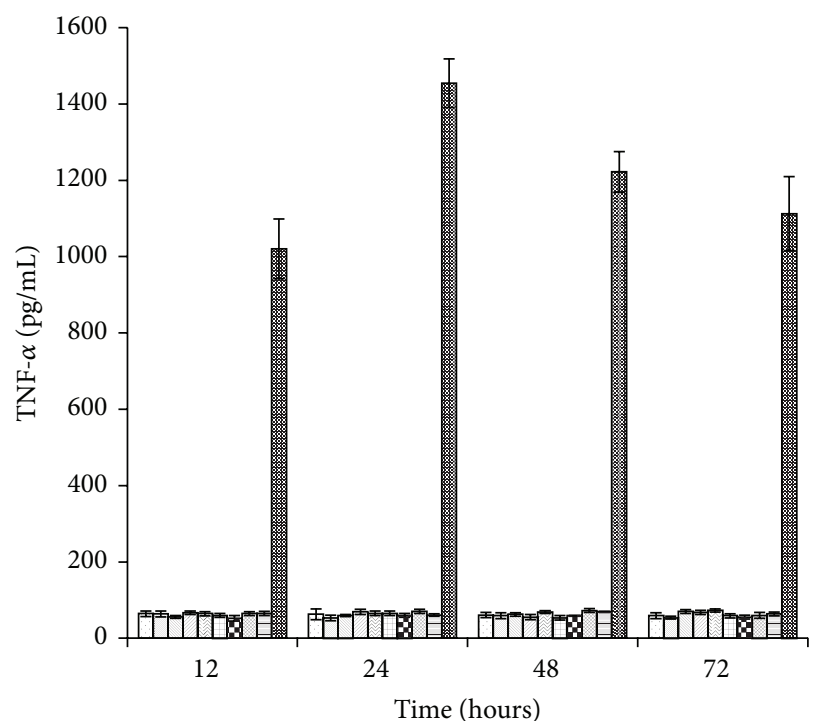
$\square$ Negative control
$1 \mu \mathrm{g} / \mathrm{mL}$ MWCNT-COOH
$1 \mu \mathrm{g} / \mathrm{mL}$-MWCNT
๑ $10 \mu \mathrm{g} / \mathrm{mL}$-MWCNT
$100 \mu \mathrm{g} / \mathrm{mL}$ p-MWCNT
ㄴ. $200 \mu \mathrm{g} / \mathrm{mL}$-MWCNT
다 $10 \mu \mathrm{g} / \mathrm{mL}$ MWCNT-COOH
․ $100 \mu \mathrm{g} / \mathrm{mL}$ MWCNT-COOH
目 $200 \mu \mathrm{g} / \mathrm{mL}$ MWCNT-COOH
[. Positive control

(d)

Figure 2: The impact of p-MWCNTs and MWCNTs-COOH on the production of cytokines in RAW264.7 cells. (a) IL-1 $\beta$, (b) IL-12, (c) IL-10, and (d) TNF- $\alpha$.

confirming the reactivity of the RAW264.7 cells to the inflammatory stimuli. To learn if the CNTs would affect the phagocytic activity of the macrophages, p-MWCNTs or MWCNTs-COOH at a concentration of $200 \mu \mathrm{g} / \mathrm{mL}$ were injected into the peritoneal cavity of mice and the murine peritoneal macrophages were harvested 24 hours later to assess the phagocytic activity. As demonstrated in Table 1, $\mathrm{PR}$ was $25.13 \pm 6.79 \%, 26.67 \pm 5.46 \%, 48.38 \pm 3.74 \%$, and $17.17 \pm 4.35 \%$ for the $\mathrm{p}$-MWCNTs exposure group, MWCNTs- $\mathrm{COOH}$ exposure group, LPS exposure group, and negative control, respectively, whereas PI was $0.804 \pm 0.068$, $0.795 \pm 0.113,1.929 \pm 0.203$, and $0.542 \pm 0.069$ for the p-MWCNTs exposure group, MWCNTs-COOH exposure group, LPS exposure group, and negative control, respectively. These results indicated that both p-MWCNTs and MWCNTs- $\mathrm{COOH}$ induced moderately elevated phagocytic 


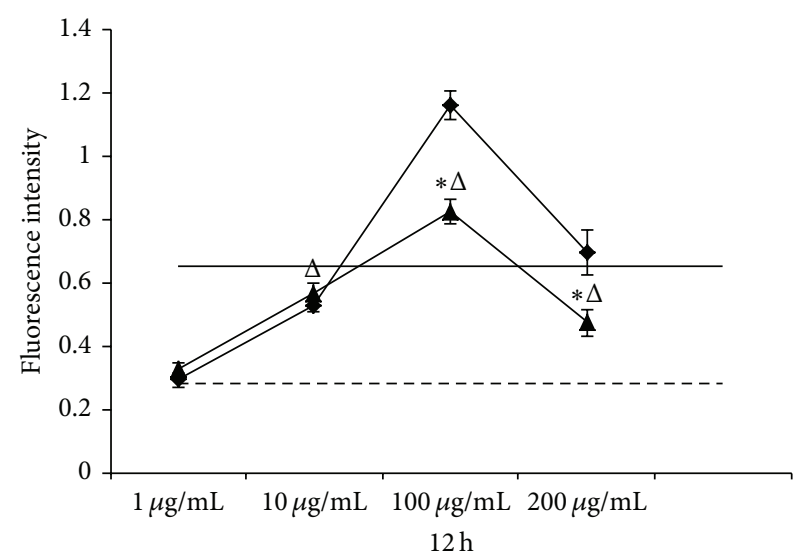

(a)

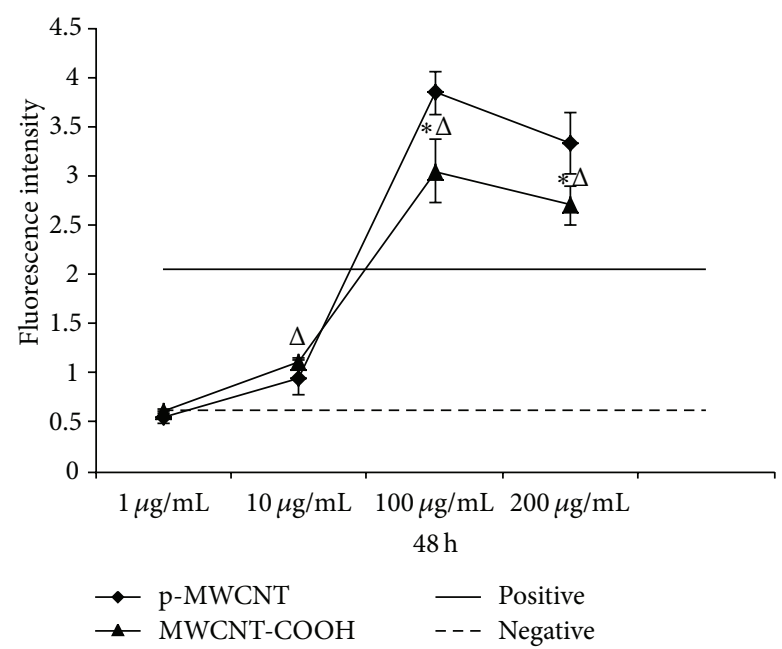

(c)

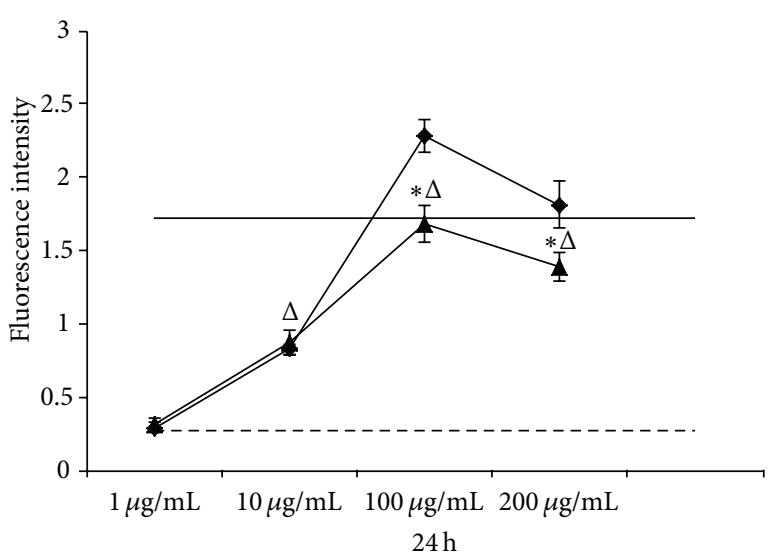

(b)

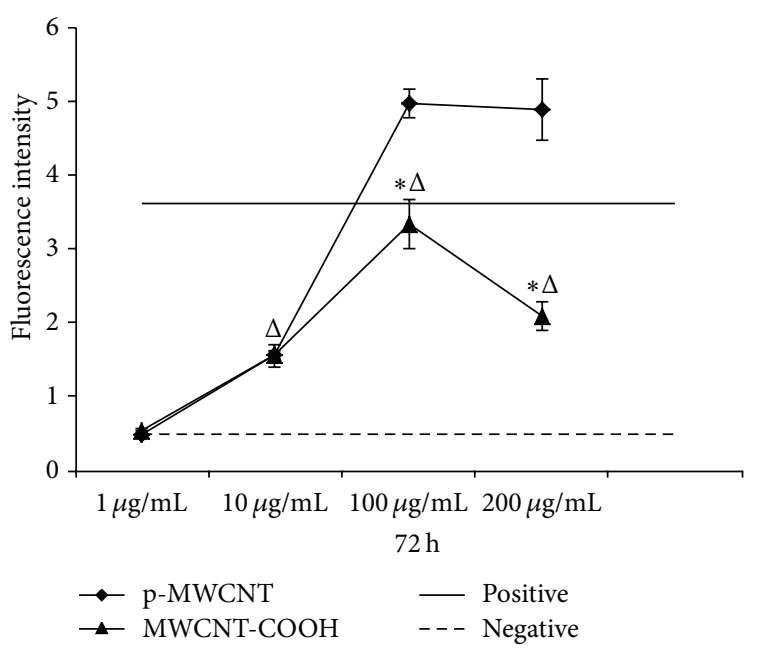

(d)

FIGURE 3: Production of ROS induced by exposure to the CNTs. ${ }^{\Delta} P<0.05$ as compared with negative control. ${ }^{*} P<0.05$ as compared with p-MWCNT group.

TABLE 1: Phagocytic activity of the macrophages in contact with the carbon nanotubes.

\begin{tabular}{lcc}
\hline & Phagocytic rate (\%) & Phagocytic index \\
\hline Negative control & $17.17 \pm 4.35$ & $0.542 \pm 0.069$ \\
p-MWCNTs & $25.13 \pm 6.79^{*}$ & $0.804 \pm 0.068^{*}$ \\
MWCNTs-COOH & $26.67 \pm 5.46^{*}$ & $0.795 \pm 0.113^{*}$ \\
LPS & $48.38 \pm 3.74^{*}$ & $1.929 \pm 0.203^{*}$ \\
\hline
\end{tabular}

${ }^{*} P<0.05$ as compared with negative control.

activity of the murine peritoneal macrophages, but no statistical significance was observed between the two CNT exposure groups.

Several different mechanisms might be involved in the nanotoxicity, in which the induction of oxidative stress by free radical formation plays a critical role [35]. Reactive oxygen species (ROS) generated during the response of cells to nanomaterials including CNT $[13,14,36]$, when in excess, might cause damage to cells through oxidation of biological macromolecules including lipids, proteins, and DNA [37]. To verify whether exposure to the MWCNTs might induce production of ROS in RAW264.7 cells, intracellular ROS accumulation was determined using $2^{\prime}, 7^{\prime}$-dichlorofluorescein diacetate (DCFH-DA), a nonfluorescent compound that accumulates in cells upon deacetylation and then reacts with ROS to form fluorescent dichlorofluorescein (DCF). Figure 3 showed that ROS production increased significantly in the cells treated with p-MWCNT or MWCNT-COOH as compared with the untreated cells at each time point and concentration except $1 \mu \mathrm{g} / \mathrm{mL}$ and ROS production was even higher in the cells treated with 100 or $200 \mu \mathrm{g} / \mathrm{mL}$ of p-MWCNT than that in the cells treated with the same amount of MWCNT$\mathrm{COOH}$ at each time point. No significant difference was observed between p-MWCNT and MWCNT-COOH group at the concentrations of 1 and $10 \mu \mathrm{g} / \mathrm{mL}$. Our previous study [25] demonstrated that p-MWCNTs induced higher ROS production in $\mathrm{LO} 2$ cells and higher degree of cytotoxicity as compared with MWCNT-COOH, indicating the positive correlation of ROS production with cytotoxicity. In the present study, it was revealed that $\mathrm{p}-\mathrm{MWCNT}$ and MWCNT-COOH 
induced similar degree of cytotoxicity against RAW264.7 cells even though the intracellular ROS production generated by p-MWCNT was significantly higher than that by MWCNT$\mathrm{COOH}$ at higher concentrations. One possible explanation for this divergent finding might be that macrophages, as a kind of phagocytes, are more resistant to the ROS induced cell damage as compared to other types of cells including LO2 cells.

\section{Conclusion}

The present study compared the impact of p-MWCNT and MWCNT-COOH on RAW264.7 cells. It revealed that MWCNTs-COOH demonstrated a similar effect on RAW264.7 cells as compared with p-MWCNTs in terms of cytotoxicity, phagocytic activity, and cytokine production, although p-MWCNTs at higher concentration induced higher ROS production in the cells as compared with MWCNTs-COOH. Those data suggested that modification with carboxyl group did not exert obvious impact on the interaction of MWCNTs with macrophages.

\section{Conflict of Interests}

The authors declare that there is no conflict of interests regarding the publication of this paper.

\section{Acknowledgments}

This research was jointly supported by the National Natural Science Foundation of China (Grant nos. 81271693 and 31200674), Natural Science Foundation of Tianjin (Grant no. 11JCZDJC20300), PUMC Youth Fund, and Fundamental Research Funds for the Central Universities (Grant no. 3332013060).

\section{References}

[1] P. M. Ajayan, "Nanotubes from carbon," Chemical Reviews, vol. 99, no. 7, pp. 1787-1800, 1999.

[2] M. F. L. de Volder, S. H. Tawfick, R. H. Baughman, and A. J. Hart, "Carbon nanotubes: present and future commercial applications," Science, vol. 339, no. 6119, pp. 535-539, 2013.

[3] S. Y. Madani, N. Naderi, O. Dissanayake, A. Tan, and A. M. Seifalian, "A new era of cancer treatment: carbon nanotubes as drug delivery tools," International Journal of Nanomedicine, vol. 6, pp. 2963-2979, 2011.

[4] D. Kato and O. Niwa, "Carbon-based electrode materials for DNA electroanalysis," Analytical Sciences, vol. 29, no. 4, pp. 385392, 2013.

[5] J. Li, Y. Xue, B. Han et al., "Application of X-ray phase contrast imaging technique in detection of pulmonary lesions induced by multi-walled carbon nanotubes in rats," Journal of Nanoscience and Nanotechnology, vol. 8, no. 7, pp. 3357-3362, 2008.

[6] V. Neves, E. Heister, S. Costa et al., "Design of double-walled carbon nanotubes for biomedical applications," Nanotechnology, vol. 23, no. 36, Article ID 365102, 2012.
[7] J. Muller, F. Huaux, N. Moreau et al., "Respiratory toxicity of multi-wall carbon nanotubes," Toxicology and Applied Pharmacology, vol. 207, no. 3, pp. 221-231, 2005.

[8] C. W. Lam, J. T. James, R. McCluskey, and R. L. Hunter, "Pulmonary toxicity of single-wall carbon nanotubes in mice 7 and 90 days after intractracheal instillation," Toxicological Sciences, vol. 77, no. 1, pp. 126-134, 2004.

[9] N. A. Monteiro-Riviere, R. J. Nemanich, A. O. Inman, Y. Y. Wang, and J. E. Riviere, "Multi-walled carbon nanotube interactions with human epidermal keratinocytes," Toxicology Letters, vol. 155, no. 3, pp. 377-384, 2005.

[10] M. Bottini, S. Bruckner, K. Nika et al., "Multi-walled carbon nanotubes induce T lymphocyte apoptosis," Toxicology Letters, vol. 160, no. 2, pp. 121-126, 2006.

[11] L. Zhu, D. W. Chang, L. Dai, and Y. Hong, "DNA damage induced by multiwalled carbon nanotubes in mouse embryonic stem cells," Nano Letters, vol. 7, no. 12, pp. 3592-3597, 2007.

[12] P. M. V. Raja, J. Connolley, G. P. Ganesan et al., "Impact of carbon nanotube exposure, dosage and aggregation on smooth muscle cells," Toxicology Letters, vol. 169, no. 1, pp. 51-63, 2007.

[13] A. A. Shvedova, V. Castranova, E. R. Kisin et al., "Exposure to carbon nanotube material: assessment of nanotube cytotoxicity using human keratinocyte cells," Journal of Toxicology and Environmental Health. Part A, vol. 66, no. 20, pp. 1909-1926, 2003.

[14] V. E. Kagan, Y. Y. Tyurina, V. A. Tyurin et al., "Direct and indirect effects of single walled carbon nanotubes on RAW 264.7 macrophages: role of iron," Toxicology Letters, vol. 165, no. 1, pp. 88-100, 2006.

[15] A. Magrez, S. Kasas, V. Salicio et al., "Cellular toxicity of carbonbased nanomaterials," Nano Letters, vol. 6, no. 6, pp. 1121-1125, 2006.

[16] S. Vardharajula, S. Z. Ali, P. M. Tiwari et al., "Functionalized carbon nanotubes: biomedical applications," International Journal of Nanomedicine, vol. 7, pp. 5361-5374, 2012.

[17] E. Fröhlich, C. Meindl, A. Höfler, G. Leitinger, and E. Roblegg, "Combination of small size and carboxyl functionalisation causes cytotoxicity of short carbon nanotubes," Nanotoxicology, vol. 7, no. 7, pp. 1211-1224, 2013.

[18] Y. Ohtsuka, M. Munakata, H. Ukita et al., "Increased susceptibility to silicosis and TNF- $\alpha$ production in C57BL/6J mice," The American Journal of Respiratory and Critical Care Medicine, vol. 152, no. 6, pp. 2144-2149, 1995.

[19] B. T. Mossman and A. Churg, "Mechanisms in the pathogenesis of asbestosis and silicosis," American Journal of Respiratory and Critical Care Medicine, vol. 157, no. 5, part 1, pp. 1666-1680, 1998.

[20] A. A. Shvedova, E. R. Kisin, R. Mercer et al., "Unusual inflammatory and fibrogenic pulmonary responses to single-walled carbon nanotubes in mice," American Journal of PhysiologyLung Cellular and Molecular Physiology, vol. 289, no. 5, pp. L698-L708, 2005.

[21] S. Hirano, S. Kanno, and A. Furuyama, "Multi-walled carbon nanotubes injure the plasma membrane of macrophages," Toxicology and Applied Pharmacology, vol. 232, no. 2, pp. 244-251, 2008.

[22] C. Cheng, K. H. Müller, K. K. K. Koziol et al., "Toxicity and imaging of multi-walled carbon nanotubes in human macrophage cells," Biomaterials, vol. 30, no. 25, pp. 4152-4160, 2009.

[23] M. L. di Giorgio, S. di Bucchianico, A. M. Ragnelli, P. Aimola, S. Santucci, and A. Poma, "Effects of single and multi walled 
carbon nanotubes on macrophages: cyto and genotoxicity and electron microscopy," Mutation Research/Genetic Toxicology and Environmental Mutagenesis, vol. 722, no. 1, pp. 20-31, 2011.

[24] B. Chen, Y. Liu, W. M. Song, Y. Hayashi, X. C. Ding, and W. $\mathrm{H}$. Li, "In vitro evaluation of cytotoxicity and oxidative stress induced by multiwalled carbon nanotubes in murine RAW 264.7 macrophages and human A549 lung cells," Biomedical and Environmental Sciences, vol. 24, no. 6, pp. 593-601, 2011.

[25] Z.-B. Liu, B. Zhou, H.-Y. Wang et al., "Effect of functionalized multi-walled carbon nanotubes on L02 cells," Zhongguo Yi Xue Ke Xue Yuan Xue Bao, vol. 32, no. 4, pp. 449-455, 2010.

[26] S. Bellucci, A. Bergamaschi, M. Bottini, A. Magrini, and T. Mustelin, "Biomedical platforms based on composite nanomaterials and cellular toxicity," Journal of Physics: Conference Series, vol. 61, pp. 95-98, 2007.

[27] A. Jos, S. Pichardo, M. Puerto, E. Sánchez, A. Grilo, and A. M. Cameán, "Cytotoxicity of carboxylic acid functionalized single wall carbon nanotubes on the human intestinal cell line Caco2," Toxicology in Vitro, vol. 23, no. 8, pp. 1491-1496, 2009.

[28] H.-L. Liu, Y.-L. Zhang, N. Yang et al., "A functionalized single-walled carbon nanotubeinduced autophagic cell death in human lung cells through Akt-TSC2-mTOR signaling," Cell Death and Disease, vol. 2, article e159, 2011.

[29] A. Casey, M. Davoren, E. Herzog, F. M. Lyng, H. J. Byrne, and G. Chambers, "Probing the interaction of single walled carbon nanotubes within cell culture medium as a precursor to toxicity testing," Carbon, vol. 45, no. 1, pp. 34-40, 2007.

[30] J. M. Wörle-Knirsch, K. Pulskamp, and H. F. Krug, "Oops they did it again! Carbon nanotubes hoax scientists in viability assays," Nano Letters, vol. 6, no. 6, pp. 1261-1268, 2006.

[31] A. Casey, E. H. Herzog, M. Davoren, F. M. Lyng, H. J. Byrne, and G. Chambers, "Spectroscopic analysis confirms the interactions between single walled carbon nanotubes and various dyes commonly used to assess cytotoxicity," Carbon, vol. 45, no. 7 , pp. 1425-1432, 2007.

[32] E. J. R. Anderson, M. A. McGrath, T. Thalhamer, and I. B. McInnes, "Interleukin-12 to interleukin 'infinity': the rationale for future therapeutic cytokine targeting," Springer Seminars in Immunopathology, vol. 27, no. 4, pp. 425-442, 2006.

[33] J.-L. Mege, S. Meghari, A. Honstettre, C. Capo, and D. Raoult, "The two faces of interleukin 10 in human infectious diseases," The Lancet Infectious Diseases, vol. 6, no. 9, pp. 557-569, 2006.

[34] A. Taylor, J. Verhagen, K. Blaser, M. Akdis, and C. A. Akdis, "Mechanisms of immune suppression by interleukin-10 and transforming growth factor- $\beta$ : the role of T regulatory cells," Immunology, vol. 117, no. 4, pp. 433-442, 2006.

[35] S. Lanone and J. Boczkowski, "Biomedical applications and potential health risks of nanomaterials: molecular mechanisms," Current Molecular Medicine, vol. 6, no. 6, pp. 651-663, 2006.

[36] K. Pulskamp, S. Diabaté, and H. F. Krug, "Carbon nanotubes show no sign of acute toxicity but induce intracellular reactive oxygen species in dependence on contaminants," Toxicology Letters, vol. 168, no. 1, pp. 58-74, 2007.

[37] K. Kitagawa, M. Matsumoto, T. Oda et al., "Free radical generation during brief period of cerebral ischemia may trigger delayed neuronal death," Neuroscience, vol. 35, no. 3, pp. 551558,1990 . 

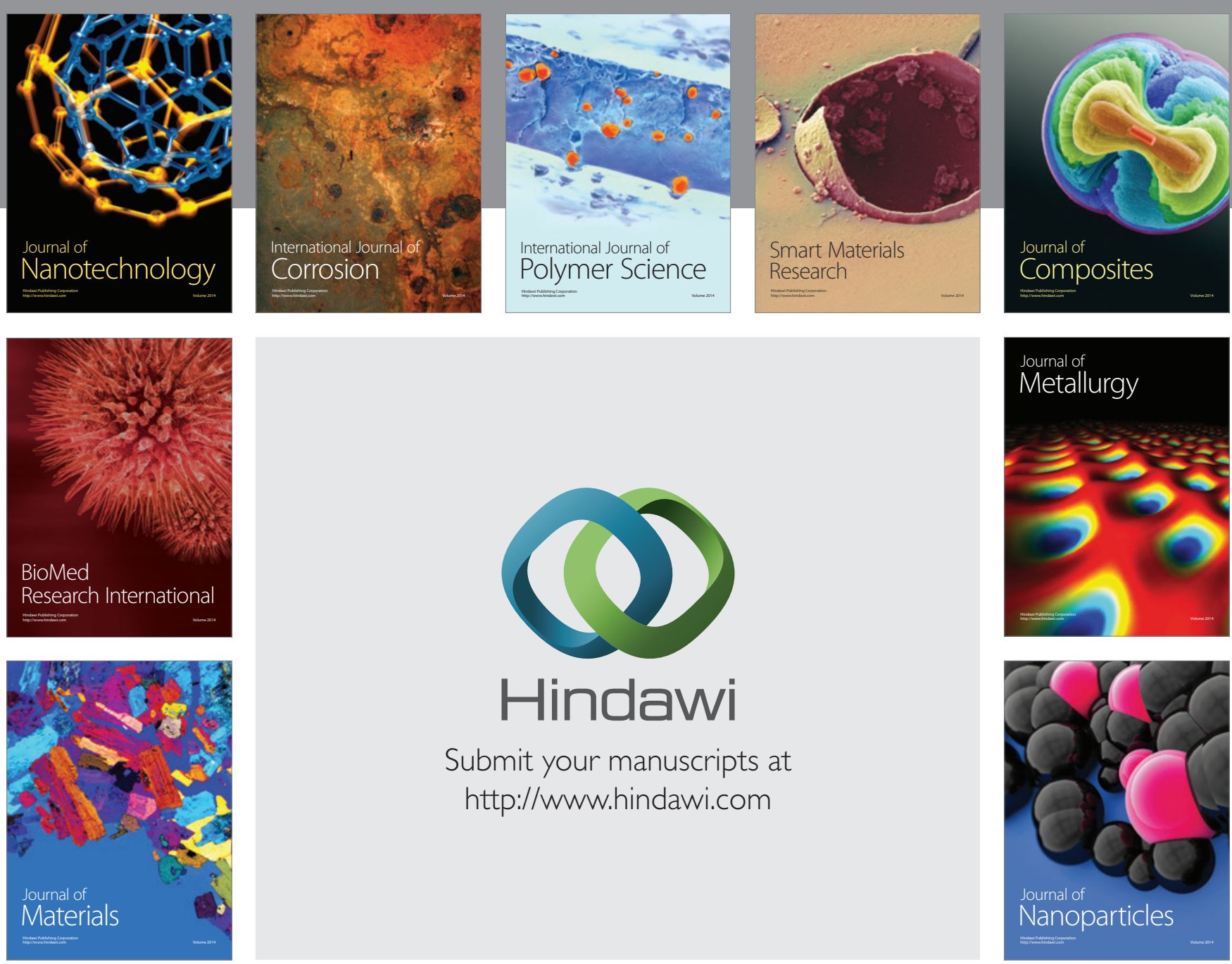

Submit your manuscripts at http://www.hindawi.com
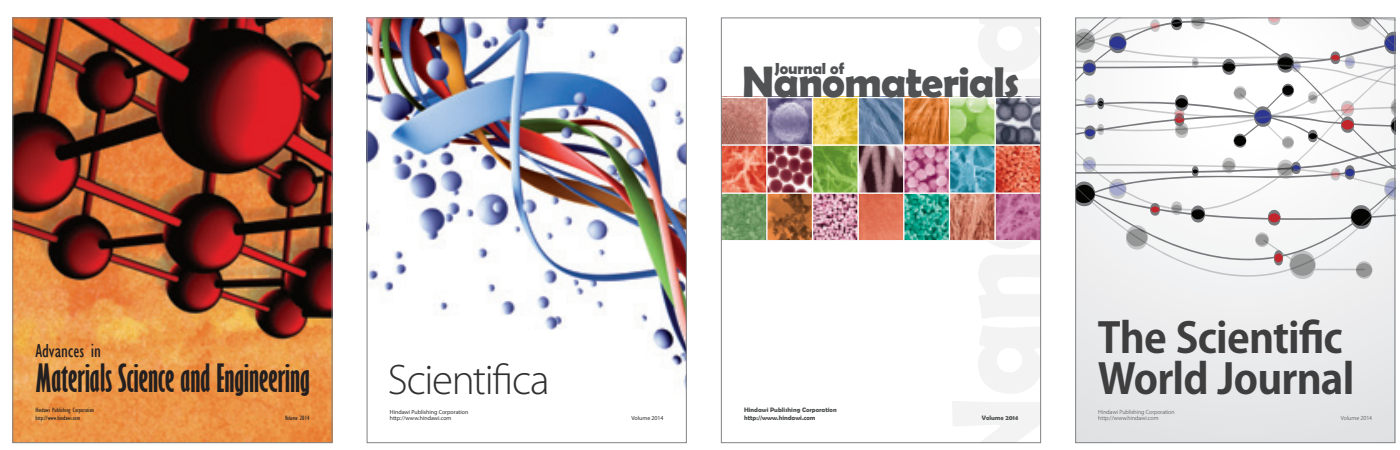

\section{The Scientific World Journal}
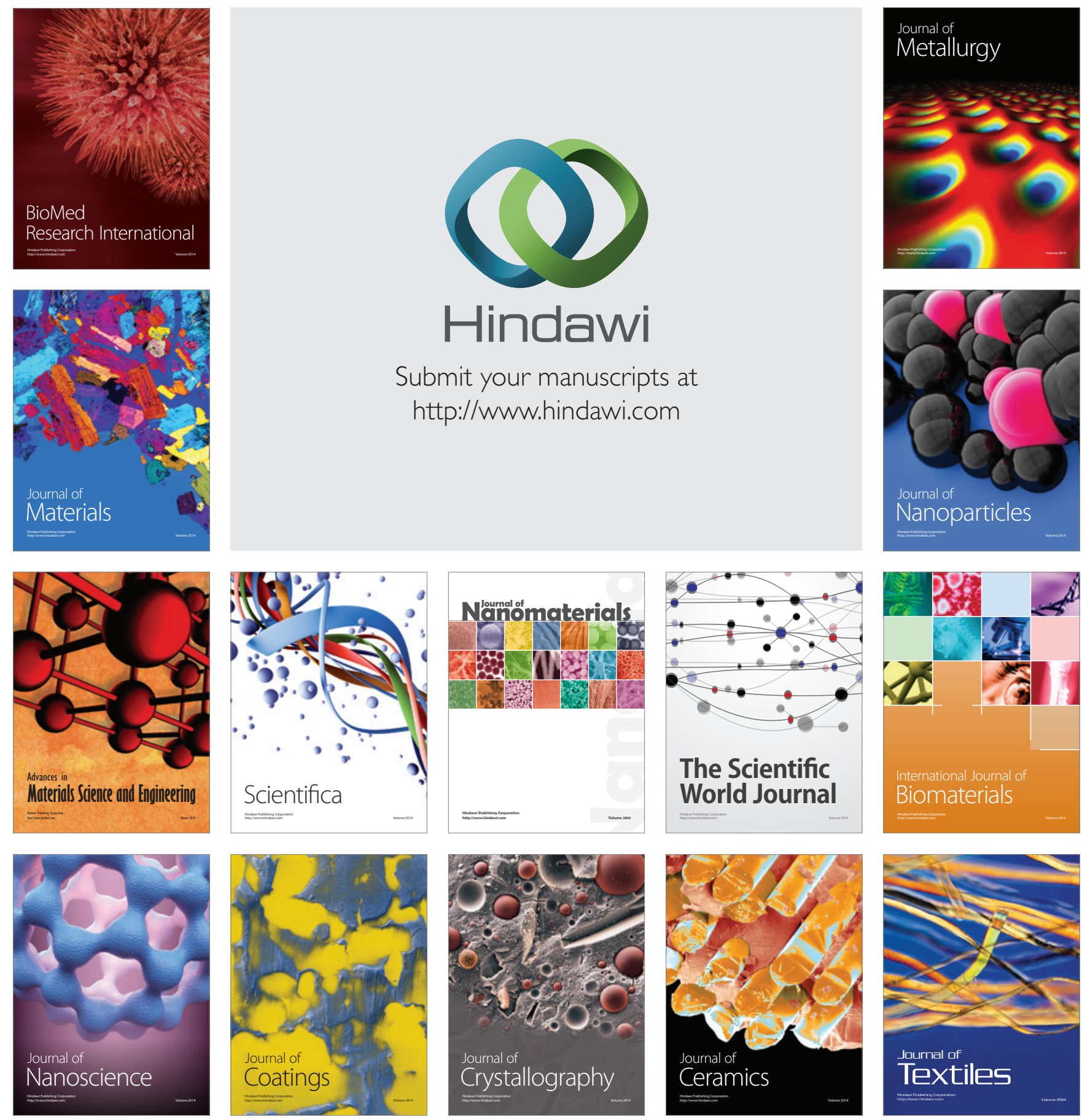